\title{
Hurbanize: uma Contribuição do Design Visual para Facilitar a Requalificação dos Espaços Urbanos
}

\author{
Hurbanize: a Contribuition of Visual Design to Facilitate the Requalification of Urban \\ Spaces
}

FERREIRA, Fernando; Bacharel em Design Visual; Programa de Pós-graduação em Design, Universidade Federal do Rio Grande do Sul - UFRGS

souza.ferreira@ufrgs.br

POZZI, Marion; Doutora em Educação; Departamento de Design e Expressão gráfica, Universidade Federal do Rio Grande do Sul - UFRGS

marionpozzi@gmail.com

SASTRE, Ricardo; Mestre em Design; Programa de Pós-graduação em Engenharia de Produção, Universidade Federal do Rio Grande do Sul - UFRGS

ricsastre@gmail.com

\section{Resumo}

O presente estudo tem por objetivo a proposição de um aplicativo capaz de permitir ao cidadão a requalificação dos espaços urbanos a partir de composições virtuais visualmente manifestas. Para tanto, a pesquisa apresenta articulações entre os conceitos de: urbanismo tático, collage e design de interação. Para a concepção da proposta do aplicativo utiliza-se como base metodológica os autores Rogers, Sharp e Preece (2013), Garrett (2011) e Munari (2008), os quais são cruzados para compor o framework proposto. O desenvolvimento do projeto passou por três pontos fundamentais: i) a verificação da proposta por meio de dinâmica de collage com estudantes de Arquitetura e Urbanismo da Universidade de Santa Cruz do Sul; ii) a construção de um protótipo para avaliação; e iii) a validação do projeto junto a representantes de três grupos do público-alvo. Por fim, as simulações visuais desenvolvidas e apresentadas aos avaliadores obtiveram nota máxima, respondendo à questão de pesquisa, de que é possível contribuir para facilitar a requalificação dos espaços urbanos a partir do ponto de vista do usuário por meio de um projeto de Design Visual.

Palavras Chave: urbanismo tático, collage, design de interação, espaço urbano.

\begin{abstract}
This work aims to create an application capable of allowing the citizen the redefinition of urban spaces by visually manifested virtual compositions. Therefore, this research presents articulations among the concepts of: tactical urbanism, collage and interaction design. For the methodological procedures, the authors: Rogers, Sharp and Preece (2013), Garrett (2011) and Munari (2008), which are cross-referenced and make up the proposed method. The development of the project went through three fundamental points: i) verification of the proposal through collage dynamics with students of Architecture and Urbanism of the University of Santa Cruz do Sul; ii) construction of a prototype for evaluation; iii) validation of the project with representatives of three groups of the
\end{abstract}


target audience. Finally, the visual simulations developed and presented to the evaluators obtained a maximum score, answering the research question that it is possible to contribute to facilitate the requalification of the urban spaces from the viewpoint of the user through a Visual Design project.

Keywords: tactical urbanism, collage, interaction design, urban space.

\section{Introdução}

Ao longo do século $\mathrm{XX}$, as cidades sofreram mudanças importantes para se adaptarem a crescente dos transportes individuais motorizados. O espaço urbano mudou sua composição e deixou de priorizar o pedestre, privando-o de espaços de estar e interagir ao ar livre para dar lugar ao tráfego e ao estacionamento de veículos, bem como a construção de avenidas e viadutos, os quais geram locais "cinza" e subutilizados. Paulatinamente, os vazios urbanos têm reduzido a interação social, causando impactos importantes na dinâmica e na infraestrutura da cidade, os quais inflamam o desejo do cidadão por melhores condições urbanas para viver.

Muitas vezes as pessoas desejam propor sugestões de melhorias para o espaço urbano a fim de promover a deliberação de uma dificuldade ou o acréscimo de uma ideia para a cidade. Entretanto, a tradução dessa idealização para um cenário pode ser uma tarefa complexa, quer por se tratar de um espaço tridimensional composto por inúmeros elementos e usos, quer pela dificuldade do cidadão em se expressar textualmente ou graficamente, ou por simplesmente não conhecer um canal para realizar tal iniciativa de forma facilitada. Por esses motivos, o projeto de design visual desenvolvido neste trabalho, propõe facilitar a manifestação de ideias para o espaço urbano como forma de contribuir para as liberdades individuais do cidadão, buscando aguçar seus valores e percepções por meio da linguagem visual, daquilo que cada indivíduo concretiza como sendo seu ideário urbano.

Por conseguinte, o estudo objetiva desenvolver a temática design e sociedade aplicada ao contexto urbano através da problemática de como um aplicativo pode facilitar a criação de requalificações para os espaços urbanos por meio de representações primariamente visuais, seguidas de complementação textual. Para isso, serão abordados os conceitos de urbanismo tático, collage e design de interação, os quais serão base para possíveis soluções criativas e interativas com o intuito de facilitar ao cidadão a explanação de ideias, instigando-o a refletir sobre o fazer da cidade. Dessa maneira, este projeto buscará responder a seguinte questão de pesquisa: a partir do ponto de vista do usuário e com o auxílio de um dispositivo móvel, é possível contribuir para a requalificação dos espaços urbanos utilizando uma ferramenta planejada pelo design visual?

Procurando responder tal questão, o trabalho estrutura-se da seguinte forma: na seção 2 , denominada referencial teórico, apresentam-se os conceitos de urbanismo tático, collage e design de interação; na seção 3, os procedimentos metodológicos e, em seguida, resultados e discussão, e, por último, as considerações finais e recomendações. Dessa maneira, busca-se, através deste artigo, que é síntese de monografia apresentada para obtenção do título de Bacharel em Design pela Universidade Federal do Rio Grande do Sul no ano de 2017, contribuir para impulsionar e difundir a pesquisa acadêmica, ademais de provocar o desenvolvimento social, particularmente no contexto urbano, estimulando a discussão sobre o Design aplicado aos problemas sociais existentes.

\section{Referencial teórico}

Nesta seção, base para a proposição do aplicativo, serão abordados os conceitos de urbanismo tático, collage e design de interação. Inicia-se pelo urbanismo tático, por requalificar os 
espaços urbanos de forma rápida e acessível. Após, é descrito o conceito de collage, que utiliza um procedimento facilitado para a composição de ressignificações. Por fim, é abordado o design de interação, que será o meio para a realização das requalificações.

\subsection{Urbanismo tático}

O urbanismo tático é uma abordagem emergente que visa intervir no espaço urbano por meio de ações rápidas e de fácil execução, a fim de demonstrar oportunidades de mudança em larga escala a longo prazo. Segundo Lydon e Garcia (2015), o urbanismo tático utiliza um processo criativo, aberto e interativo, que inclui governos, empresas e organizações sem fins lucrativos, grupos de cidadãos e indivíduos, com o intuito de promover intervenções e políticas nos espaços urbanos.

Para Kohlsdorf (1996, p.21) o "espaço urbano e a sociedade são duas faces da mesma moeda", uma vez que os lugares construídos não tomam posição estática, mas sim, seguem a gerência dos agentes sociais que ali habitam. Desta maneira, o espaço urbano está em constante transformação por possuir "qualidades físicas em convivência com seus atributos sociais". Portanto, é fundamental compreender este espaço como forma física que possui desempenho a partir das expectativas dos seus usuários. Dessa maneira, para combater a subutilização dos espaços, é imprescindível conhecer a realidade por meio da contribuição daqueles que vivenciam diariamente tais dificuldades.

Para combater tal subutilização, Lydon e Garcia (2015) apresentam três aplicações comuns do urbanismo tático. A primeira destaca a iniciativa dos cidadãos para contornar a burocracia convencional, apresentando possíveis mudanças e soluções por meio de maquetes, protótipos e idealizações visuais para o espaço urbano com o intuito de vivificar seu "direito à cidade". Tal uso comum é de interesse deste trabalho. A segunda trata das ações do urbanismo tático como ferramenta dos governos para proporcionar o engajamento de organizações sem fins lucrativos e agentes sociais no processo de composição do espaço. Já a terceira salienta a implementação "phase 0 ", que permite avaliar um projeto antes que ele receba um investimento definitivo.

Figura 1 - Urbanismo tático aplicado na Times Square em New York
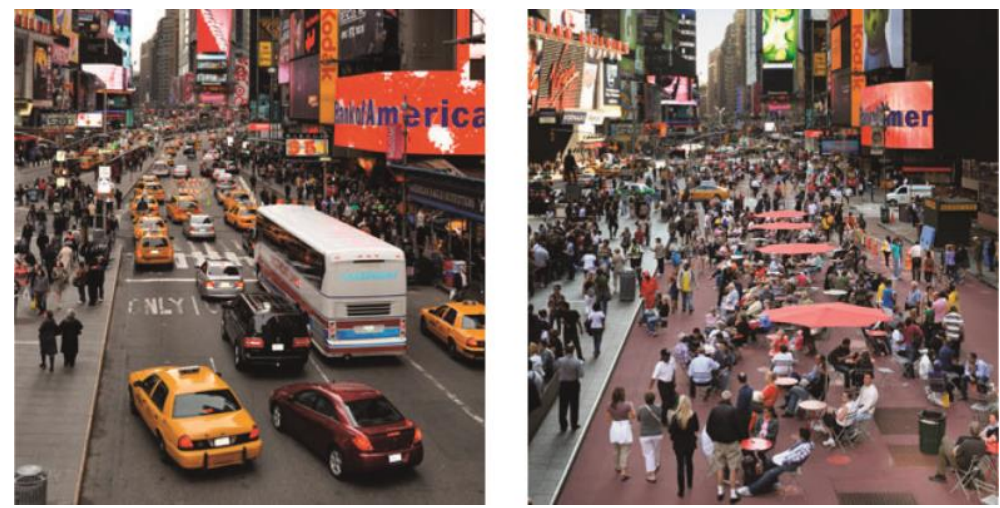

Fonte: LYDON \& GARCIA, (2015)

De acordo com os autores, o urbanismo tático é uma oportunidade para transformar o modo burocrático e lento de conceber a cidade. Recorrendo a processos de interesse, são realizadas interações e articulações entre indivíduos e entre os indivíduos e o setor público, que permitem coletar informações, obter apoio público, transformar rapidamente o espaço e gerar melhores práticas para a cidade. Tais interações e articulações são conceituadas pelos autores como processos "bottom-up, top-down", de baixo para cima, de cima para baixo (LYDON \& GARCIA, 2015, 
p.10), constatando que novas experiências podem ser geradas a partir da participação civil e dos governos municipais.

Geralmente as ações do urbanismo tático acontecem nas ruas, por se tratarem de locais com grande atividade social. Tais ações buscam configurar o resgate dos espaços subutilizados e a reintegração das ruas pelos pedestres. Lydon e Garcia (2015) classificam como play streets (ruas de lazer) e open streets (ruas abertas) as ações que reaproveitam temporariamente as ruas para fomentar o lazer social. Os autores também apresentam atividades que utilizam vagas de estacionamento para instalação de pequenos parques temporários para uso dos cidadãos, com o intuito de evidenciar a problemática carros versus pedestres.

\subsection{Collage}

A imagem é nosso primeiro meio para apreensão do mundo. Segundo Lima (1984), é preciso valorizá-la como recurso para tradução da imaginação frente ao texto. Assim, as imagens são uma forma de linguagem que transcende a escrita, por não possuir linearidade. Na collage as imagens se relacionam simultaneamente para a construção e representação do imaginário como forma de expressar um contexto específico, um cenário dado. Conforme Fuão (1996), as imagens são atuantes em nosso processo cognitivo de tal maneira que nosso inconsciente nos fala por meio delas. Por meio da collage tudo pode ser modificado em seu significado e aspecto. À vista disso, Ernst (1982), citado por Fuão (2011, p. 9), define collage como sendo "a transfiguração de todas as coisas e seres, em uma mudança de significado". Logo, a collage utiliza elementos existentes para criar composições e ressignificações, que não se preocupam com a relação correta entre perspectivas e escalas dos elementos, mas sim com a transmissão de um conceito. Conforme Fuão (2017) a Collage é um processo de associação de formas e ideias - é uma maneira de permitir que o mundo fale por meio de suas imagens, signos e fragmentos. Desse modo, a collage se diferencia da "colagem": enquanto a primeira é uma forma de linguagem que visa expressar desejos e emoções, a segunda é o tratamento dado a um material.

Geralmente, collages são concebidas a partir de elementos impressos e fotografias. Trata-se de um ato consciente, uma saída à condição passiva do observador frente a uma fotografia do espaço (FUÃO, 1992). Fuão (2011) caracteriza o processo da collage em quatro etapas: recorte, fragmentos, encontros e cola. O recorte presume a escolha e extração de determinados elementos a partir do desejo do autor e, segundo Fuão (2017), a tela do computador e dos celulares sensíveis ao toque ainda configuram tal incisão, mesmo que de forma digital. Os fragmentos são os materiais resultantes da operação anterior e também podem ser utilizados na configuração da collage. Os encontros tratam de casar as figuras e os fragmentos recortados com o intuito de gerar ressignificações, muitas vezes ocasionadas pela sorte. Já a cola tem como objetivo fixar as figuras entre si ou a composição em um suporte. Segundo o autor, a partir de cada etapa é revelado o significado de cada ato, removendo a neutralidade dos elementos e apresentando figuras repletas de significados.

A remoção de superficialidade das figuras é um dos objetivos da collage. Por meio de gestos rasos, da manipulação de objetos existentes, geralmente vulgares, a collage produz novas imagens que falam por si para o mundo, revelando o que se esconde em seu interior - o significado, o conceito. Fuão (2011) destaca que a collage é constituída por dois sentidos: a errância e a espera. A errância são as figuras selecionadas que irão transitar sobre a espera. Dessa forma, a espera é o cenário ou suporte sobre o qual os elementos da errância serão compostos. Portanto, neste 
trabalho, a espera será uma fotografia do espaço urbano e a errância serão todos os elementos urbanos disponibilizados gráfica e virtualmente no aplicativo para uso do cidadão. A (figura 2) apresenta um exemplo da técnica de Collage.

Figura 2 - "Porto de Rio Grande", 1998

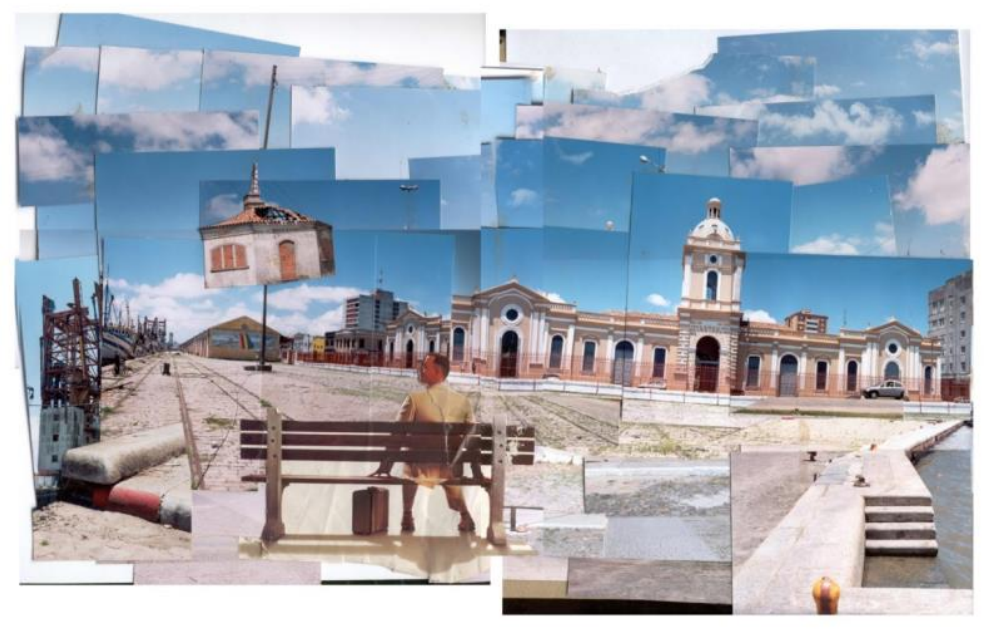

Fonte: FUÃO, (2011)

De acordo com Fuão (2011), a collage é capaz de questionar o mundo através da simplicidade de suas figuras, moldando-o e redescobrindo-o juntamente com seu usuário. O meio adotado para promover as ressignificações urbanas foi o design de interação, tema a ser expandido a seguir.

\subsection{Design de interação}

O design de interação trata da experiência do usuário frente à utilização de uma aplicação. Nos últimos tempos, foram desenvolvidas inúmeras tecnologias que propiciaram a concepção de diferentes interações do usuário. Rogers, Sharp e Preece (2013) destacam que os especialistas têm mesclado o meio físico e o digital para promover novas experiências e usos como: realidades mistas, realidades aumentadas e interfaces tangíveis, assim como de interfaces que apoiam interações sociais para determinados grupos de pessoas, indo além do usuário individual.

Por se tratar de uma área abrangente, o design de interação é tratado pelas autoras como sendo o termo guarda-chuva para as áreas de design de interface do usuário, projeto de software, design centrado no usuário, web design, design de experiência e design de sistemas interativos. Ademais, compreendem que o design de interação apoia a criação de usos e experiências que melhorem e ampliem o modo como os usuários se comunicam, trabalham e interagem. Para tanto, o design de interação busca reduzir as frustrações dos usuários, ao mesmo passo que procura ampliar o divertimento e comprometimento dos mesmos com a aplicação, tratando de desenvolver produtos cada vez mais eficientes e agradáveis ao uso.

Garrett (2010) expõe que qualquer produto utilizado por alguém pressupõe experiência de usuário. A experiência do usuário trata de analisar o desempenho do produto frente sua utilização (ROGERS; SHARP; PREECE, 2013), ou seja, diz respeito a como as pessoas se sentem, se elas têm prazer e satisfação ao utilizar determinado produto. Entretanto as autoras ressaltam que a experiência não deve ser projetada como fim em si, apenas pelo fato de propor a experimentação de algo, uma vez que esse algo não é objetivo do produto a ser desenvolvido. Assim a experiência deve seguir como solução para a realização de uma tarefa considerando aspectos de usabilidade, 
funcionalidade, estética e conteúdo do sistema, bem como aspectos sensoriais e emocionais do usuário. Além disso, a experiência pode alcançar aspectos ainda mais subjetivos, como o engajamento social via redes sociais e o compartilhamento de valores e de identidade cultural.

Para refletir sobre o projeto da experiência do usuário, Nilsen (1995) propôs as 10 heurísticas da usabilidade, que buscam, através de itens generalistas e subjetivos, aperfeiçoar as interfaces e os arranjos lógicos do produto. Dessa maneira, são utilizadas na orientação do design pretendido e na avaliação da usabilidade do sistema. Sintetizadas pelo autor, as heurísticas derivam de 249 problemas de usabilidade, são elas: visibilidades do status do sistema; correspondência entre o sistema e o mundo real; controle do usuário e liberdade; consistência e padrões; prevenção de erros; reconhecimento em vez de lembrança; flexibilidade e eficiência de uso; estética e design minimalista; ajudar os usuários a reconhecer, diagnosticar e a se recuperar de erros; ajuda e documentação.

\subsection{Aproximações teóricas}

A partir da aproximação teórica da triangulação de pesquisa - urbanismo tático, collage e design de interação - foi desenvolvido o conceito do projeto com o propósito de formatar uma novidade. Assim, cria-se uma relação de equilíbrio entre as partes, na qual cada uma delas empresta qualidades a fim de almejar o objetivo do projeto, formando uma "nuvem" de expressões que representa a intenção conceitual deste trabalho (figura 3 ).

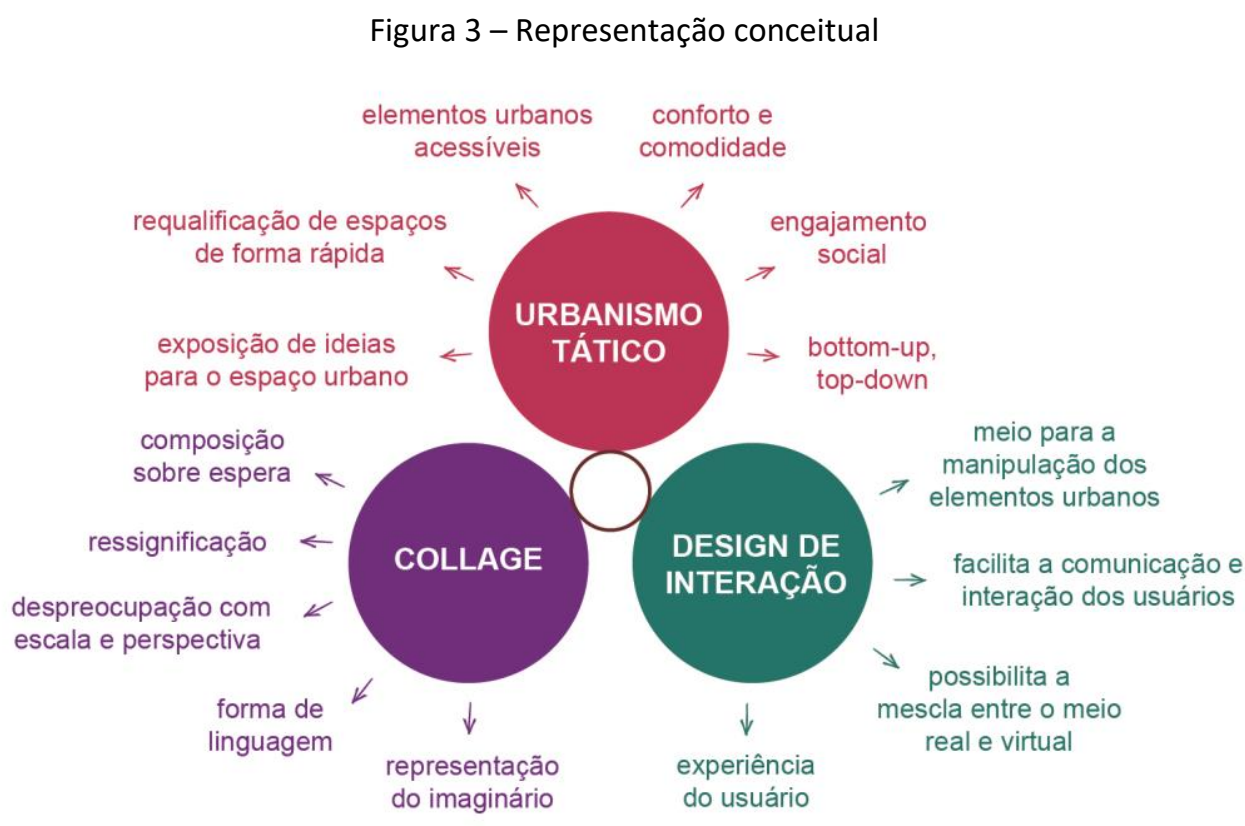

Fonte: Os autores

\section{Procedimentos metodológicos}

O método de pesquisa, de natureza exploratória, busca, através do levantamento bibliográfico, subsídios para a proposição do método de desenvolvimento do artefato fruto deste trabalho. À vista disso, o framework proposto combina as teorias de Rogers, Sharp e Preece (2013), Garrett (2011) e Munari (2008).

Rogers, Sharp e Preece (2013) apresentam um processo cíclico em macro etapas, que possibilita sua retomada para promover melhorias constantes na aplicação. Já Garrett (2011) 
demonstra um método prático, que leva do abstrato ao concreto, porém, sem validar aquilo que foi construído. Por fim, Munari (2008) expõe uma metodologia com pesquisa e levantamento de dados, além de processos de verificação com o usuário. Dessa maneira, o framework proposto é composto por cinco macro etapas e suas subdivisões, buscando combinar as características cíclicas, práticas, de pesquisa e avaliativas dos autores citados acima, além de trazer à tona as heurísticas de Nilsen (1995) como diretrizes a serem consideradas permanentemente no projeto. Com tais propriedades, o processo apresenta a reflexão constante daquilo que está sendo desenvolvido, por meio de orientações, verificações e análises juntamente com os usuários. Isto posto, segue a estrutura do método proposto (figura 4) bem como a descrição dos seus itens.

Figura 4 - Estrutura do framework proposto

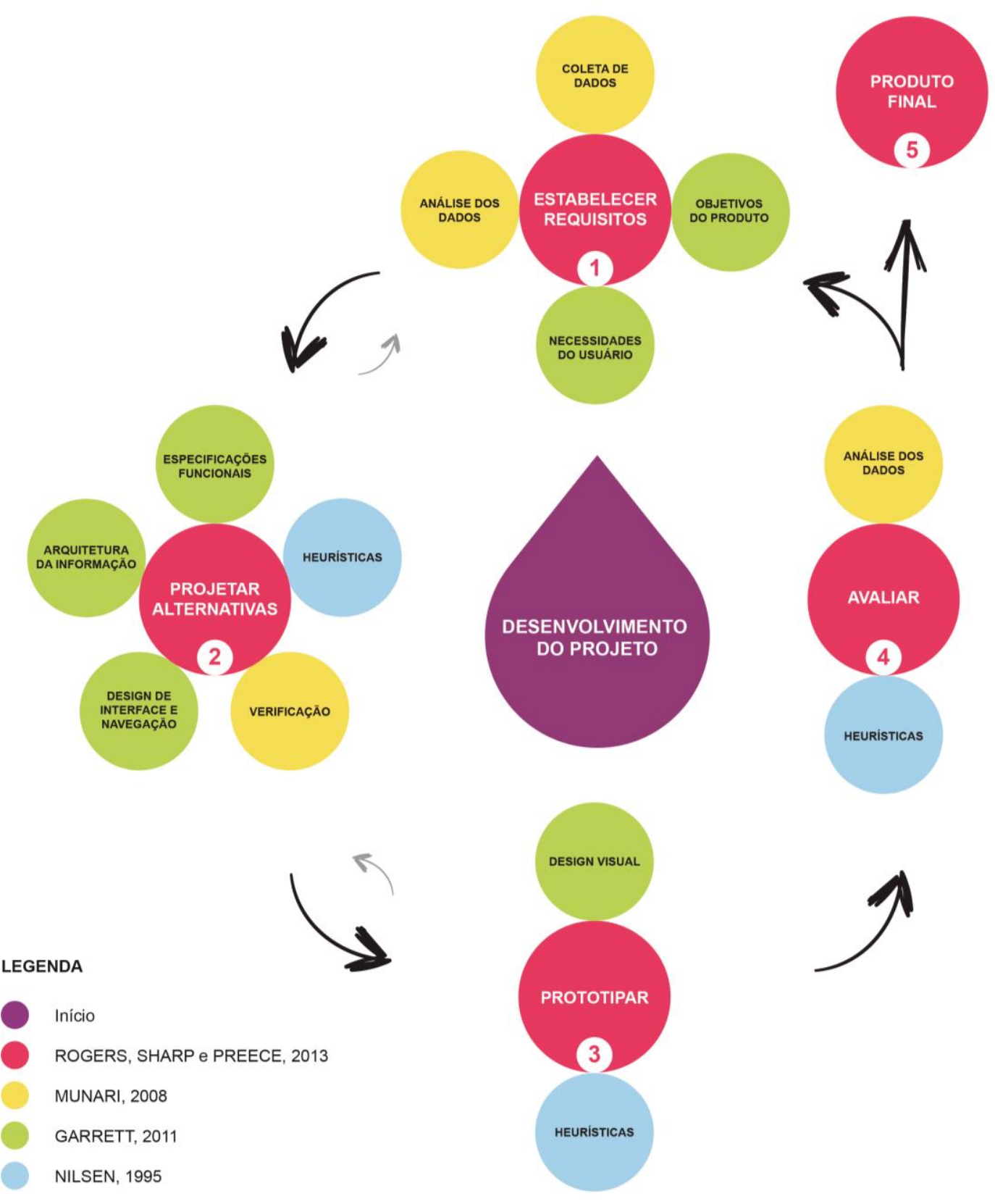

Fonte: os autores 
Etapa 1 - Estabelecer requisitos: i) Coleta de dados: nessa etapa está prevista a pesquisa por similares, pesquisa exploratória, entrevistas e o desenvolvimento de personas; ii) Análise dos dados: segundo Munari (2008), a análise dos dados busca averiguar como foram resolvidos problemas parecidos em projetos anteriores, além de obter informações do público-alvo; iii) Necessidades do usuário: definem-se as necessidades do usuário por meio das informações levantadas anteriormente e do processo interpretativo dos papéis e intenções dos usuários; iv) Objetivos do produto: levando em consideração o processo interpretativo dos papéis e intenções dos usuários, são definidos os objetivos da responsabilidade do sistema, que visam solucionar o problema de projeto.

Etapa 2 - Projetar alternativas: i) Especificações funcionais: segundo Garrett (2011), nessa etapa são definidas as funções capazes de cumprir com os objetivos estipulados anteriormente no projeto, obtendo como resultado o escopo da interface; ii) Arquitetura da informação: é o momento em que se define a organização da navegação para que o usuário acesse o conteúdo de forma eficiente e eficaz, resultando na estrutura do produto; iii) Interface e navegação: nessa etapa são desenvolvidos os wireframes, que são modelos simplificados das telas do produto digital; iv) Verificação: apresenta-se os modelos simplificados das telas para alguns usuários, com o intuito de que eles possam opinar sobre a proposta em desenvolvimento; v) Heurísticas: para essa etapa deverão ser consideradas as heurísticas de Nilsen (1995) relativas aos aspectos de funcionais, organizacionais e de navegação da aplicação, como forma de orientar o design pretendido.

Etapa 3 - Prototipar: i) Heurísticas: para essa etapa deverão ser consideradas as heurísticas de Nilsen (1995) que possuem relação com os aspectos referentes ao design visual do projeto; ii) Design visual: é desenvolvida nessa etapa a identidade e os elementos gráficos juntamente com sua diagramação para compor a interface do produto digital.

Etapa 4 - Avaliar: i) Heurísticas: nessa etapa será avaliado o produto a partir das heurísticas de Nilsen (1995). Para tanto, serão realizados testes com os usuários para conferir o atendimento dos objetivos do produto, das necessidades dos usuários e das heurísticas estipuladas; ii) Análise dos dados: a partir do levantamento de dados anterior, são realizadas análises para aprovação ou então a realização de melhorias no projeto, retomando o ciclo da metodologia representado na (figura 4).

Etapa 5 - Produto final: Resultados alcançados no projeto, neste caso a solução e desdobramentos do protótipo proposto.

\section{Resultados e discussão}

O desenvolvimento do projeto segue a estrutura do framework proposto.

Etapa 1 - Estabelecer requisitos: nessa etapa foram estabelecidos os requisitos do produto a partir da síntese do conceito, dos objetivos do projeto e dos aspectos contextuais envolvidos. Tais requisitos serviram como diretrizes e apoiaram o desenvolvimento das alternativas do produto.

Análise de similares: foram eleitas quatro aplicações digitais, a partir das suas características e da intenção desta proposta para serem analisadas. São elas: Snapchat, Streetmix, Colab e Instagram. Para analisá-las, foram propostos critérios a partir dos planos do método de Garrett (2011). Para o plano da estrutura, o critério de análise é o mapeamento da arquitetura geral da informação. Para o plano do esqueleto, a interação da navegação. Para o plano do escopo, os conteúdos e funções. Para o plano do design visual, os atributos visuais. Já para o plano da 
estratégia, o relacionamento com o usuário.

A partir de tal análise, o projeto proposto tem o intuito de utilizar algumas funcionalidades e convenções apresentadas pelos similares de forma adaptada. Tanto a funcionalidade histórias do Snapchat quanto o histórias do Instagram são voltadas para publicações de no máximo 24 horas. Logo, não utilizam a composição de imagens como forma de expô-las na linha do tempo, tampouco apresentam elementos urbanos para a utilização do usuário, sendo totalmente voltadas para o entretenimento. Diferentemente dessa prática, a proposta do projeto a ser desenvolvido busca trabalhar com composições para os espaços urbanos, disponibilizando seus elementos de forma ilustrada, assim como o site Streetmix faz. Porém a utilização de tais elementos será realizada sobre uma fotografia de um ambiente real, conferindo a possibilidade para sua requalificação.

Personas: segundo Sharp, Rogers e Preece (2013), a técnica da criação de personas consiste na elaboração de perfis que descrevem um conjunto de usuários comuns do produto em desenvolvimento. Assim, cada persona representa um segmento de usuários alvo, apresentando informações sobre seus aspectos comportamentais e de interesses, além de nome, idade, formação e cargo. Tal técnica busca permitir que o designer de interação se coloque no lugar do usuário final de forma empática, facilitando a sua tomada de decisão sobre as funcionalidades, as interações e a estética do produto para a construção de uma experiência agradável.

Segundo Marcos Oliveira (2017), ativista urbano e colaborador do grupo Shoot the Shit, as características do público-alvo podem ser definidas a partir de duas perspectivas: o ativista e o voluntário. $\mathrm{O}$ ativista caracteriza um grupo de pessoas que atuam, de fato, sobre as questões urbanas, possuem experiência e consciência da importância do que estão fazendo. Já o voluntário representa um grupo de pessoas que são interessadas pela causa, participam de debates sobre questões urbanas e estão em processo de transição para a realização das ações no ambiente urbano.

Definição dos requisitos: os requisitos do design de interação possuem diferentes características. Com a finalidade de facilitar sua compreensão, foram categorizados em: requisitos funcionais, de usabilidade e de dados. Os requisitos funcionais dizem respeito às funcionalidades que o sistema deve ter para que seu objetivo seja alcançado. Os requisitos de usabilidade tratam da qualidade da interface e sua navegação, para que o usuário possa realizar a tarefa utilizando o menor esforço possível. Por fim, os requisitos de dados se referem às informações que os usuários necessitam acessar para realizar as tarefas. Assim sendo, seguem abaixo os requisitos gerais do projeto.

Requisitos funcionais: o projeto do aplicativo deve permitir: a captura fotográfica; a manipulação virtual dos elementos urbanos baseada no conceito de collage; a complementação textual para as composições virtuais; o compartilhamento das idealizações com os demais usuários do sistema e também para fora dele; a colaboração dos demais usuários sobre uma ideia publicada de forma escrita, sinalizada ou visualmente manifesta; a impressão da publicação; o colecionamento de publicações de interesse; o acesso aos perfis de outros usuários; a classificação de uma publicação como inapropriada; o mapeamento das composições publicadas.

Requisitos de usabilidade: o projeto da ferramenta deve considerar as 10 heurísticas de usabilidade de Nilsen (1995) para a construção de um processo facilitado, criativo, aberto e interativo à criação de intervenções virtuais para a dimensão setorial dos espaços urbanos. 
Requisitos de dados: a ferramenta deve apresentar o mapeamento das intervenções virtuais publicadas, questões informacionais de perfil do usuário e de uso do aplicativo, bem como os elementos categorizados em: urbanização e delimitadores, descanso, iluminação, jardinagem e água, comunicação, serviço público, comerciais e limpeza.

Dinâmica de verificação: com o objetivo de verificar a receptividade e percepção do públicoalvo à ideia, foi realizada junto a estudantes de arquitetura e urbanismo da Universidade de Santa Cruz do Sul, no mês de outubro de 2017, uma dinâmica de collage na qual se disponibilizaram cenários urbanos, ilustrações dos elementos urbanos e revistas, a fim de promover um debate sobre a proposta. A partir dos materiais disponibilizados e de uma explanação conceitual sobre collage, os estudantes partiram para a prática. Nela puderam extrapolar a pratica projetual de modo conceitual, visto que, nesse caso, não precisavam se preocupar com adequação de escala e com a representação em perspectiva, mas sim, se ater a utilizar sua criatividade e senso crítico para propor ideias que pudessem transformar a dinâmica social do cenário disponibilizado em um cenário pretendido.

No debate, os estudantes salientaram o potencial de expor ideias que a collage permite, como uma forma simples e rápida para visualizar ensaios de urbanismo tático. Outro apontamento fundamental do público-alvo foi a necessidade de se disponibilizar personagens, calungas, como elementos do cenário urbano, a fim de representar dinâmicas sociais na composição da intervenção. Finalmente, a dinâmica agradou ao público e foi percebida como um facilitador para exposição de ideias para dimensão setorial do espaço urbano.

Etapa 2 - Projetar alternativas: nesta etapa foram desenvolvidas as especificações funcionais, a arquitetura da informação e o design de interface e navegação do projeto, orientados pelas heurísticas de Nilsen (1995).

Especificações funcionais: a partir da responsabilidade do sistema, bem como dos requisitos de ordem funcional, foram levantadas as especificações funcionais que a ferramenta deve conter para que o usuário possa atingir seus objetivos e os objetivos do projeto. Tais especificações serão base para o desenvolvimento da arquitetura da informação: i) possibilitar a captação e composição de imagens com elementos urbanos ilustrados e seu compartilhamento na aplicação e para fora dela; ii) permitir que os usuários sinalizem e comentem nas publicações de outros usuários; iii) propiciar que os usuários tenham acesso a imagem publicada para sugerir ideias a partir de uma nova composição, seguida da sua publicação como comentário na postagem original; iv) possibilitar o acesso de um usuário ao perfil e publicações de outro usuário; v) possibilitar a impressão da composição publicada; vi) permitir que o usuário colecione publicações que ele quer seguir contribuindo; vii) disponibilizar mapa e geolocalização.

Arquitetura da informação: busca compreender o funcionamento do sistema de modo geral. Tal estrutura visa relacionar o fluxo de telas em forma de diagrama. Na arquitetura da informação, inicia-se a transição entre elementos abstratos para fatores mais concretos do produto, visando organizar, hierarquizar e dispor o conteúdo com o intuito de facilitar o aprendizado do usuário de forma intuitiva. Para tanto, foram exploradas algumas alternativas.

A partir das alternativas e da priorização para a função principal do sistema, a tela "câmera", foi definido a seguinte sequência geral de telas, levando em consideração o acesso do usuário de

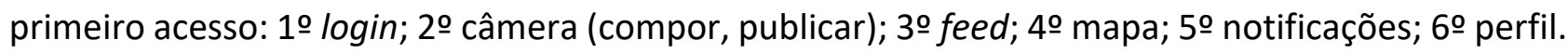


Design de interface e navegação: visa diagramar a informação em um conjunto lógico de telas, para que os usuários atinjam seus objetivos utilizando o menor esforço. A criação de variações para as alternativas levou em consideração as características de interesse dos similares. Com base nessas variações, foram consultadas a opinião do público-alvo e as heurísticas de Nilsen (1995). As três principais decisões tomadas para construção do wireframe final, a partir das características de consistência, controle e liberdade apresentadas pelos similares analisados foram: i) a decisão da tela "câmera" ser a principal foi tomada a partir da heurística de consistência apresentada pelo similar Snapchat, cujo qual possui foco na publicação, característica de interesse deste projeto; ii) a decisão de disponibilizar um menu na base, fixo, para navegação foi tomada a partir da heurística de controle e liberdade, que é trabalhada com qualidade pelo similar Instagram; iii) a decisão de disponibilizar aspectos de edição livre, como a função "caneta" e a manipulação dos elementos urbanos ilustrados na tela "compor", foi tomada a partir das consistências apresentadas pelos similares Instagram e Snapchat nas suas respectivas funções "histórias".

Etapa 3 - Prototipar: nessa etapa foi desenvolvido o design visual da proposta. À vista disso, foram escolhidos os elementos urbanos ilustrados, o desenvolvimento do nome, o desenvolvimento da marca Hurbanize, o sistema visual Material Design e o design visual do sistema.

Elementos urbanos ilustrados: as ilustrações foram classificadas em três listas e cinco categorias, com o intuito de serem disponibilizadas ordenadamente no aplicativo. São elas: 1 ) sinalização, vegetação e barreiras; 2) descanso e serviço público; 3) calungas. O objetivo de tal classificação é proporcionar conhecimento e familiaridade sobre a funcionalidade de cada elemento urbano ao usuário do aplicativo. Além disso, a classificação em apenas três listas visa facilitar a usabilidade do sistema, fazendo com que o usuário acesse as 55 ilustrações com, no máximo, dois comandos de navegação.

Desenvolvimento do nome e marca: o processo de desenvolvimento de um nome para o sistema partiu do conceito deste trabalho. Foram elencadas palavras-chave, como collage, urbanismo e exposição para serem utilizadas como ponto de partida para um processo de brainwriting. O brainwriting consiste em desencadear novas ideias a partir de associações a um conceito inicial. Conforme as ideias surgem, novas possibilidades conceituais nascem. Portanto, trata-se de um processo rico, por permitir que se explorem aspectos não lógicos do conceito de referência. A partir disso, o nome escolhido para o presente estudo foi Hurbanize, uma brincadeira com as palavras Humanizar e Urbanizar, que foi traduzido na marca produzida, a partir da técnica de collage (figura 4).

Figura 4 - Marca Hurbanize

\section{HORPMNIIIZZE}

Fonte: os autores

Material design: para iniciar o desenvolvimento das interfaces, fez-se necessário a tomada de decisão entre os sistemas Android, IOS ou Windows Phone. Segundo o relatório apresentado pela IDC (2017), empresa de consultoria em Tecnologia da Informação, o sistema Android possui $85 \%$ da fatia total de mercado, sendo assim, é amplamente utilizado. Logo, este projeto será desenvolvido para tal sistema. Com a decisão tomada, conferiu-se que o Android possui uma 
linguagem visual própria, o Material Design. Segundo a Google Design (2017), o Material Design foi criado para estabelecer um idioma, unir um estilo de branding e interação, por meio de um conjunto de princípios coesos para o desenvolvimento de um design adequado. À vista disso, esse conjunto será base para o desenvolvimento do design visual deste projeto. Desse modo, alguns dos princípios a serem seguidos foram: i) família tipográfica; ii) construção de ícones; iii) métricas; iv) cores.

Design visual do aplicativo: segue as diretrizes do Material Design bem como a heurística da estética minimalista de Nilsen (1995), sendo concebido em 360x640dp. Com o intuito de promover a identidade visual, o sistema é setorizado a partir das cores da marca: a tela "câmera" recebeu pitadas de amarelo, a tela "feed" verde, a tela "mapa" magenta, a tela "perfil" violeta, e, a tela "notificações" um tom de cinza. Consequentemente, as ramificações a partir destas telas principais carregarão as cores determinadas. Portanto, além de transmitir certa alegria, o design visual do sistema também auxilia o usuário a compreender a origem das suas ações através da setorização das cores, o que também é trabalhado de forma mais acentuada pelo similar Snapchat.

Etapa 4 - Avaliar: a validação do sistema foi realizada a partir do parecer do público-alvo sobre um protótipo através do software de prototipação Adobe XD. Foram delegadas algumas tarefas para que os avaliadores explorassem o aplicativo de modo geral, simulando as tarefas dentro daquilo que o protótipo permitia. A exploração do sistema partiu da função principal, tirar uma foto, setorizar um espaço com a caneta, aplicar no mínimo um elemento de cada uma das três listas, escrever uma legenda e publicar. Após, foi realizada a navegação pelas telas mapa, notificações, perfil e feed. Na tela feed os usuários conferiram comentários, antes e depois das composições e impressão da publicação em PDF.

Realizadas as tarefas delegadas, o público respondia a um questionário que continha três questões de múltipla escolha e duas de parágrafo livre. A primeira questão solicitava que os usuários adjetivassem o aplicativo a partir dos adjetivos apresentados nos aspectos da experiência do usuário. Tratavam-se de quinze adjetivos, positivos e negativos, dos quais os usuários deveriam assinalar três, $20 \%$ do total, direcionando seu foco para os de maior importância. Já a segunda pergunta foi baseada nas heurísticas de Nilsen (1995) e apresentava quatro afirmações sobre a aprendizagem do aplicativo. Assim, os usuários davam notas de 1 a 4, onde 1 discordava da afirmação e 4 concordava com a afirmação. Para a terceira questão, foi apresentado o objetivo desta pesquisa em forma de pergunta, na qual os usuários opinaram sobre o quanto a proposta apresentada a eles facilitaria a manifestação visual de ideias para o espaço urbano. Por fim, a questão quatro tratava da explanação de alguma avaliação negativa e a cinco de sugestões a serem avaliadas.

Foram consultados cinco avaliadores, sendo três de cunho ativista voluntário e dois ativistas. Os de cunho voluntariado são estudantes do curso de Arquitetura e Urbanismo da Universidade de Santa Cruz do Sul e haviam participado da atividade de collage realizada anteriormente. Já os ativistas são de Porto Alegre, um representante do grupo Shoot the Shit e outro formando em Arquitetura e Urbanismo pela UFRGS.

Para a primeira questão, os adjetivos mais selecionados foram: interessante, prestativo, apoia a criatividade, divertido e instigante. A leitura dessa questão é positiva, uma vez que não foram assinalados adjetivos negativos. Dessa maneira, a experiência, mesmo que em um protótipo, satisfez o público consultado. A segunda questão também recebeu parecer positivo, visto que as afirmações não obtiveram notas abaixo de 3 , sendo que $80 \%$ das respostas concordaram de forma 
integral com as afirmações heurísticas apresentadas. Já na terceira questão, os respondentes confirmaram o objetivo geral desta pesquisa, assinalando a nota 4 (facilitaria muito), oposta à nota 1 (não facilitaria), para a utilidade da proposta em facilitar a manifestação visual de ideias para o espaço urbano. Por fim, na questão cinco, campo de sugestões e expressão, os usuários realizaram sínteses positivas da ideia apresentada, confirmando, assim, a assimilação do conceito da proposta.

Etapa 5 - Produto final: para apresentação do produto final foi necessário realizar alguns ajustes considerados na validação do sistema pelos usuários. Com o produto ajustado, apresentase e descreve-se funcionalmente as principais telas do aplicativo.

Telas principais do sistema: uma vez realizado o cadastramento, o usuário terá acesso a todas as telas do aplicativo bem como suas funções. Assim, poderá navegar a partir e entre as telas câmera, feed, mapa, notificações e perfil (figura 5).

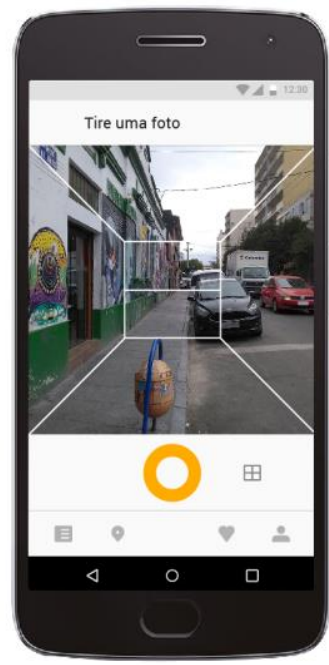

3. Tela câmera (Home)

Figura 5 - Interfaces principais do aplicativo

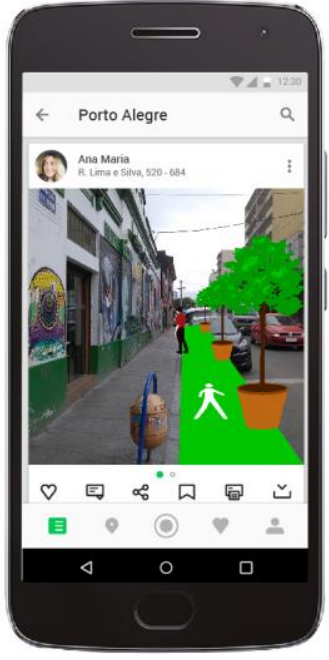

4. Tela feed

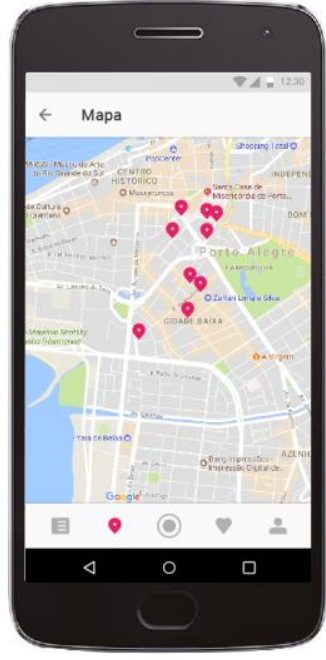

5. Tela mapa

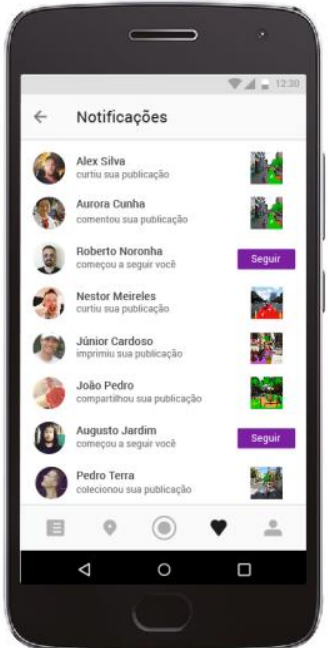

6. Tela notificações

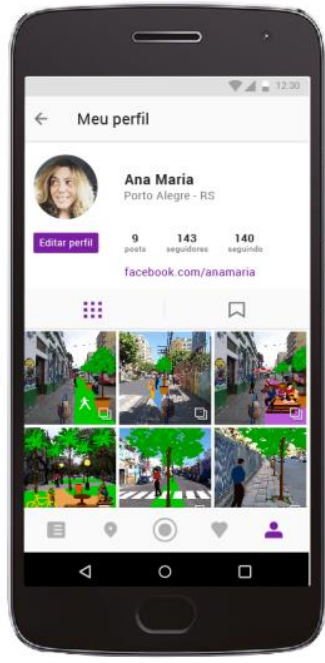

7. Tela perfil

Fonte: os autores

Desdobramentos da tela câmera: a tela câmera possui duas sequências de desdobramentos. A primeira é a partir da captura de uma fotografia e, a segunda a partir do resgate de uma fotografia na galeria de imagens do smartphone. No primeiro caso, o usuário será direcionado para a "Tela compor", na qual poderá acessar a "Tela caneta edição livre" bem como os "Elementos de sinalização, vegetação e barreiras", "Elementos de descanso e serviço público" e os "Elementos calungas". Com sua composição realizada, o usuário poderá "Confirmar composição", sendo então direcionado para "Editar endereço" e "Finalizar e publicar composição". Já no segundo caso, o usuário será direcionado para "Buscar imagem na galeria". Ao selecionar uma imagem, será levado para "Recortar imagem da galeria" a fim de colocá-la nos padrões exigidos pelo sistema. Feito isso, será direcionado para cumprir fluxo idêntico ao do primeiro caso.

Desdobramentos da tela feed: a tela feed possui muitas funções. Uma delas é acessar a "Tela da publicação", na qual o usuário poderá conferir todos os comentários, localização e sinalizações positivas. Também poderá realizar um comentário por dois meios. O primeiro é de forma escrita, através da tela "Adicionar comentário". Já o segundo acontecerá quando o usuário clicar no ícone de "anexar uma imagem", sendo então direcionado para a tela "adicionar comentário e anexar composição", onde seguirá o fluxo apresentado anteriormente da "Tela compor". Satisfeito da sua 
composição, o usuário será direcionado para "Finalizar e publicar comentário".

Desdobramento da tela mapa: o desdobramento da tela mapa é "Conferir conteúdo do apontamento no mapa", onde o usuário poderá navegar entre os pontos sem precisar acessar a tela da publicação de fato.

Desdobramentos da tela perfil: a tela perfil possui quatro desdobramentos principais: acessar a "Tela coleção", "Editar perfil", "Seguidores" e "Seguindo".

A atuação do aplicativo sobre o espaço e suas potencialidades se dá em: i) grande atuação (figura 6): áreas carentes de espaços verdes; espaços de estar ao ar livre; espaços subutilizados ou abandonados; sobras de planejamento sem uso; bloqueios da circulação do pedestre no passeio público; ii) média atuação: áreas carentes de equipamentos; áreas com grande circulação de pedestres e ciclistas; áreas de alto tráfego de veículos motorizados; áreas de conflito entre carros e pedestres; iii) pequena atuação: vazios periféricos; margens de águas; áreas com vistas privilegiadas; áreas industriais desativadas ou subutilizadas; lajes e coberturas sem uso; terrenos contaminados.

Figura 6 - Exemplo de possíveis requalificações a partir do aplicativo.

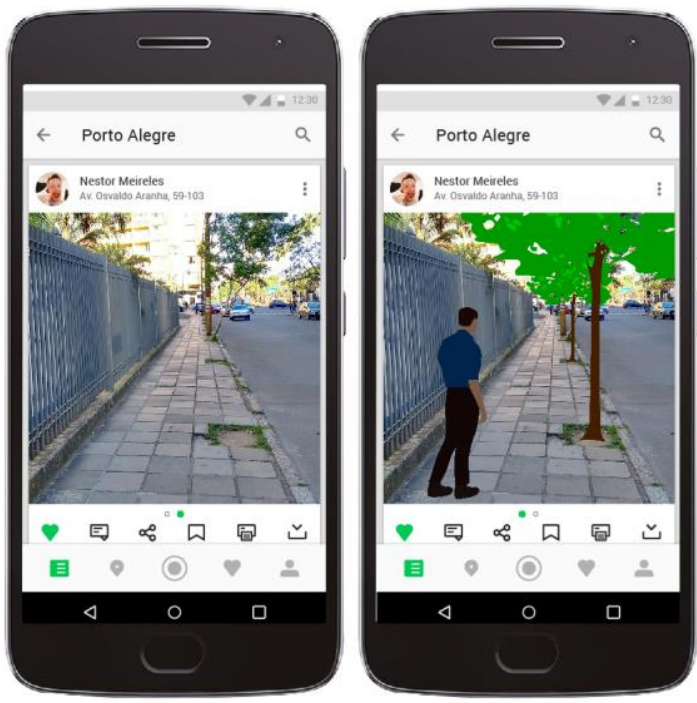

Áreas carentes de espaços verdes

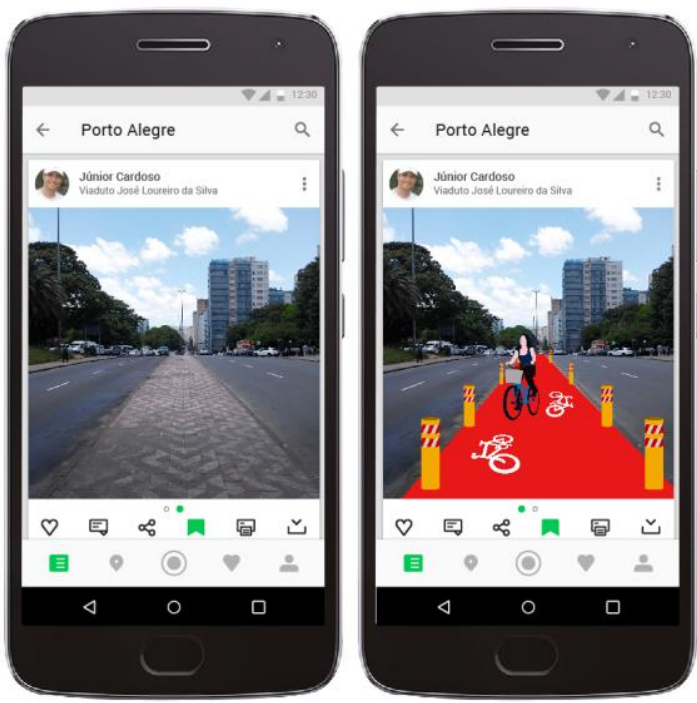

Sobras de planejamento sem uso

Fonte: os autores

\section{Considerações finais}

É importante destacar que este trabalho visou aguçar no cidadão valores e percepções por meio da linguagem visual, daquilo que cada indivíduo concretiza como sendo seu ideário urbano. Buscou-se possibilitar um processo criativo, aberto e interativo para a composição de idealizações visuais dos espaços urbanos, com o intuito de requalificá-los de forma facilitada. À vista disso, procurou-se incentivar a apreensão do espaço pelo cidadão a partir do arranjo e da composição dos elementos virtuais aplicados na forma urbana com a finalidade de criar cenários que despertassem reações emocionais em seu imaginário. Tal objetivo buscou a conscientização e o engajamento dos cidadãos para construção coletiva da cidade, com o intuito de promover a deliberação para o entendimento e a formação de valores, tornando-se, assim, um canal de consulta e troca entre cidadãos e entre cidadãos e especialistas. 
Assim como na primeira aplicação comum do urbanismo tático de Lydon e Garcia (2015), este trabalho buscou evitar meios convencionais lentos para propor de forma visual possibilidades de mudança para os espaços urbanos, idealizando e requalificando ambientes de forma virtual, através da contribuição daqueles que vivenciam diariamente as dificuldades citadinas. Além disso, visou estimular a interação entre pessoas interessadas pelas causas urbanas, a divulgação impressa das composições, o acesso a grupos de debate e o mapeamento das oportunidades para melhoria urbana.

Por fim, as simulações visuais desenvolvidas e apresentadas aos avaliadores obtiveram nota máxima, respondendo a questão de pesquisa de que é possível contribuir para facilitar a requalificação dos espaços urbanos, a partir do ponto de vista do usuário, por meio de um projeto de Design Visual. Recomenda-se, para trabalhos futuros, um estudo sobre a viabilidade de implementação do aplicativo proposto, a validação com um grupo maior de pessoas e um possível estudo a partir da segunda aplicação comum do urbanismo tático apresentada por Lydon e Garcia (2015), que trata do interesse dos governos em promover o engajamento dos cidadãos no processo de construção da cidade.

\section{Referências}

FUÃO, F. F. Arquitectura como Collage. Tese Doutoral. Escuela Técnica Superior de Arquitectura de Barcelona. Universit Politeecnica de Catalunya, 1992.

FUÃO, F. F. A Collage como Trajetória Amorosa. Porto Alegre: Editora da UFRGS, 2011.

FUÃO, F. Entrevista escrita. Fernando Fuão: Collage. [jul. 2017]. Entrevistador: Fernando Ferreira. Porto Alegre, 2017.

GARRETT, J. J. The Elements of User Experience: User-centred design for the web and beyond. 2nd. ed. Berkeley: New Riders, 2011.

GOOGLE DESIGN. Design is Never Done. Disponível em: https://design.google/library/design-neverdone/. Acesso em: 19 nov. 2017.

IDC, Analyze the Future. Relatório Smartphone OS Market Share, 2017 Q1. Disponível em: https://www.idc.com/promo/smartphone-market-share/os. Acesso em: 18 nov. 2017.

KOHLSDORF, M. E. A Apreensão da Forma da Cidade. Brasília: Fundação Universidade de Brasília, 1996.

LIMA, S. F. Collage em nova Superfície. São Paulo: Editora Parma. 1984.

LYDON, M.; GARCIA, A. Tactical Urbanism: Short-term Action for Long-term Change. New York: Island Press, 2015.

MUNARI, B. Das coisas nascem coisas. São Paulo: Martins Fontes, 2008.

NIELSEN, J. 10 Usability Heuristics for User Interface Design. jan 1995. Disponível em: http://www.nngroup.com/articles/ten-usability-heuristics/. Acesso em: 25 jun 2017.

OLIVEIRA, M. Entrevista Ações no Espaço Urbano. [jul. 2017]. Entrevistador: Fernando Ferreira. Porto Alegre, 2017. 1 arquivo .mp3 (38 min.).

ROGERS, Y.; SHARP, H.; PREECE, J. Design de Interação: Além da interação humano-computador. 3 ed. Porto Alegre: Bookman, 2013. 